\title{
ProcReACIÓN NATURAL VERSUS ECTOGÉNESIS
}

\author{
P. Hoces-Guerrero ${ }^{1}$ \\ C. Nique Carbajal ${ }^{2}$
}

\section{Sr. Editor}

La vida humana se inicia con la fecundación, gracias a la unión de los gametos femenino y masculino, que dan origen al cigoto, el cual cuenta con un genoma individual derivado de ambos progenitores; posteriormente, el cigoto se implanta en el útero para dar paso al embarazo. Hoy en día, cerca del $15 \%$ de parejas en edad fértil tienen problemas para conseguir un embarazo de forma natural. Por ello, con la intención de brindar apoyo extracorpóreo para la procreación se implementaron las técnicas de reproducción humana asistida (TRHA), que con el nacimiento de L. Brown en 1978, del primer "bebé probeta", han ido evolucionando para ayudar a superar los problemas de infertilidad (1).
Para lograr sus fines, la TRHA recurre a distintos métodos como la maternidad subrogada o vientre de alquiler, y también a técnicas en desarrollo como la ectogénesis, con su proyecto "Útero artificial o Biobag" (2017), la misma que puede ser de tipo parcial, donde los sujetos se desarrollan en el útero antes de ser transferidos, y la completa, donde su desarrollo es totalmente en la Biobag (2). Con respecto al útero de alquiler, el abogado Noel Keane, en 1976, realizó el primer contrato legal de gestación subrogada y en 1980 se firmó el primer acuerdo de subrogación compensada. Actualmente, esta técnica es un fenómeno comercial global y existen diversas agencias encargadas de su desarrollo (3).

DOI: 10.5294/pebi.2021.25.2.3

PARA CITAR ESTA CARTA / TO REFERENCE THIS LETTER / PARA CITAR ESTA CARTA

Hoces-Guerrero P. Ñique C. Procreación natural versus ectogénesis. Pers Bioet. 2021;25(2):e2523. DOI: https://doi.org/10.5294/pebi.2021.25.2.3

1 Estudiante, Facultad de Ciencias de la Salud, Escuela profesional de Medicina Humana, Universidad Señor de Sipan, Perú.

2 Docente, Facultad de Ciencias de la Salud, Escuela profesional de Medicina Humana, Universidad Señor de Sipan, Perú. 
Para efectos de comparar los usos, las aplicaciones e implicancias bioéticas entre la maternidad subrogada y la ectogénesis se realizó una investigación bibliográfica sobre estos procesos. En nuestro análisis se encontró que la ectogénesis parcial reduciría las altas tasas de morbimortalidad entre los prematuros, y sería la mejor alternativa a las cámaras incubadoras neonatales; es posible asumir que esto traería cuestionamientos sobre el aborto por su impacto en la viabilidad del feto, mientras que en la ectogénesis total se visualizan los dilemas éticos de la realización de investigaciones con embriones humanos (4). En la subrogación se puede pensar que las mujeres deben mantener el autocontrol y la libertad total de sus cuerpos, pero esta práctica se ejerce en un contexto social que reduce sus cuerpos a objetos; si bien ofrece una fuente de ingresos para las más desfavorecidas, estas no eligen libremente porque viven coaccionadas por la pobreza, además son adoctrinadas para ignorar lazos con el bebé, desnaturalizando su trabajo y degradando la maternidad. Así mismo, algunas agencias de subrogación someten a las madres a grandes regímenes, llegando a aislarlas para un mayor control (3); la ectogénesis, por su parte, plantea subcontratar una máquina que monitorearía cuidadosamente cada momento de la vida del feto, lo que ayudaría a discernir sus implicancias éticas, lo que facilitaría las intervenciones al tratarlo de forma independiente (3). La observación recae en que se involucra a dos pacientes, equiparando las responsabilidades morales entre los intereses fetales y maternos (4). Si objetamos que la maternidad es un obstáculo en el camino hacia la emancipación de la mujer podríamos establecer que la ectogénesis las liberaría, mejorando sus derechos y permitiendo con esto que ellas compartan el trabajo de gestación con los hombres, aunque esta acción podría romper la relación entre madre, feto y maternidad (5).
Al comparar ambas técnicas, tal como se muestra en la tabla 1, podemos concluir que si se llegara a desarrollar la ectogénesis, esta podría convertirse en una alternativa más eficiente que la maternidad subrogada, lo que traería un mayor beneficio en su aplicación; sin embargo, no podemos ignorar los grandes dilemas éticos que implica su uso, por lo cual se requiere un mayor análisis antropológico y biomédico para su aplicación, que responda a la cuestión de si todo lo técnicamente posible (de llegar hacerlo) es éticamente correcto.

Tabla 1. Comparación de la utilidad y las implicancias bioéticas entre el útero artificial y el útero de alquiler

\begin{tabular}{|c|c|c|}
\hline & UTILIDAD & $\begin{array}{l}\text { IMPLICANCIAS } \\
\text { BIOÉTICAS }\end{array}$ \\
\hline \multirow{6}{*}{ 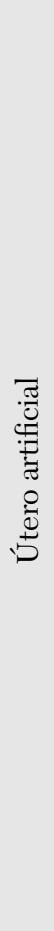 } & $\begin{array}{l}\text { Reducción de } \\
\text { morbimortalidad en } \\
\text { prematuros antes de las } 24 \\
\text { semanas. }\end{array}$ & $\begin{array}{c}\text { Cuestiones legales y éticas } \\
\text { sobre los derechos del } \\
\text { aborto al determinar su } \\
\text { viabilidad. }\end{array}$ \\
\hline & $\begin{array}{c}\text { Subcontrata el embarazo a } \\
\text { una máquina. }\end{array}$ & $\begin{array}{c}\text { Solución a la subrogación } \\
\text { materna. }\end{array}$ \\
\hline & $\begin{array}{c}\text { Desarrollo completo } \\
\text { del feto fuera del útero } \\
\text { materno. }\end{array}$ & $\begin{array}{c}\text { Dilemas morales sobre } \\
\text { las investigaciones con } \\
\text { embriones humanos. }\end{array}$ \\
\hline & $\begin{array}{c}\text { Facilitar las intervenciones } \\
\text { fetales. }\end{array}$ & $\begin{array}{c}\text { Responsabilidades morales } \\
\text { entre los intereses fetales y } \\
\text { los intereses de la madre. }\end{array}$ \\
\hline & $\begin{array}{l}\text { Monitoreo total del feto } \\
\text { mediante una máquina. }\end{array}$ & $\begin{array}{l}\text { Rompe el vínculo entre } \\
\text { madre, feto y maternidad. }\end{array}$ \\
\hline & $\begin{array}{c}\text { Liberar a las mujeres } \\
\text { del rol de la maternidad } \\
\text { permitiendo que } \\
\text { compartan el trabajo de } \\
\text { gestación con los hombres. }\end{array}$ & $\begin{array}{l}\text { Rompe el vínculo de entre } \\
\text { madre, feto y maternidad. }\end{array}$ \\
\hline
\end{tabular}




\begin{tabular}{|c|c|c|}
\hline & UTILIDAD & $\begin{array}{l}\text { IMPLICANCIAS } \\
\text { BIOÉTICAS }\end{array}$ \\
\hline \multirow{5}{*}{ 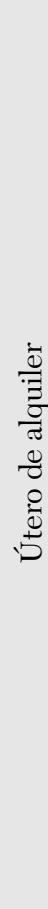 } & $\begin{array}{l}\text { Mujeres con autocontrol } \\
\text { total de sus cuerpos. }\end{array}$ & $\begin{array}{l}\text { Reducción de sus cuerpos a } \\
\text { objetos, lo que las convierte } \\
\text { en seres desechables. }\end{array}$ \\
\hline & $\begin{array}{l}\text { Fuente de ingresos para las } \\
\text { mujeres desfavorecidas. }\end{array}$ & $\begin{array}{c}\text { Mujeres coaccionadas por } \\
\text { la pobreza y la falta de } \\
\text { oportunidades. }\end{array}$ \\
\hline & $\begin{array}{l}\text { Contratos precisos que } \\
\text { protegen los derechos de la } \\
\text { mujer subrogada. }\end{array}$ & $\begin{array}{c}\text { Las mujeres no eligen } \\
\text { libremente ya que carecen } \\
\text { de suficiente información } \\
\text { sobre riesgos para su salud. }\end{array}$ \\
\hline & $\begin{array}{c}\text { Mujeres renuncian } \\
\text { a sus derechos y } \\
\text { responsabilidades sobre el } \\
\text { bebé. }\end{array}$ & $\begin{array}{c}\text { Las madres desnaturalizan } \\
\text { su trabajo y degradan la } \\
\text { maternidad. }\end{array}$ \\
\hline & $\begin{array}{l}\text { Las madres se someten } \\
\text { a grandes regímenes, } \\
\text { aislándolas de sus familias } \\
\text { para aumentar control y } \\
\text { vigilancia. }\end{array}$ & $\begin{array}{c}\text { Los regímenes comparten } \\
\text { paralelismos con la } \\
\text { esclavitud. }\end{array}$ \\
\hline
\end{tabular}

\section{REFERENCIAS}

1. Gamboa Bernal G. Las técnicas de reproducción asistida (TRA) a la luz de la bioética. Rev Escritos. 2016;24(53):322-6. DOI: http://dx.doi.org/10.18566/escr.v24n53.a05

2. Partridge E, Davey M, Hornick M, McGovern P, Mejaddam A, Vrecenak J. et al. An extra-uterine system to physiologically support the extreme premature lamb. Rev Nature Commun. 2017;8(1):2-14. DOI: https://doi.org/10.1111/ bioe.1268210.1038/ncomms15112

3. Deonandan R. Thoughts on the ethics of gestational surrogacy: Perspectives from religions, Western liberalism, and comparisons with adoption. J Assis Reprod Gen. 2020; 37(2):26979. DOI: https://doi.org/10.1007/s10815-019-01647-y

4. Di Stefano L, Mills C, Watkins A, Wilkinson D. Ectogestation ethics: The implications of artificially extending gestation for viability, newborn resuscitation and abortion. Rev Bioet. 2019;34(4):371-84. DOI: https://doi.org/10.1111/bioe.12682

5. Rozée V, Unisa S, La Rochebrochard E. The social paradoxes of commercial surrogacy in developing countries: India before the new law of 2018. BMC Women's Health. 2020;20(1):2-13. DOI: https://doi.org/10.1186/s12905-020-01087-2 